\title{
FAMILIAL DYSAUTONOMIA
}

\author{
BY \\ T. MCKENDRICK \\ From the Paediatric Unit, Hillingdon Hospital, Middlesex \\ (RECEIVED FOR PUBLICATION APRIL 11, 1958)
}

Familial dysautonomia is a rare syndrome of childhood affecting the nervous system. As the name suggests, dysfunction of the autonomic system is a prominent feature. It was first recognized as a separate entity by Riley, Day, Greeley and Langford (1949), the first large series being described by Riley (1952). So far, about 70 patients have been recorded. Though the fully developed syndrome is unmistakable, not all its features can be elicited in infancy and it is likely that some patients have died undiagnosed. Some of the constituent features may suggest other commoner diseases such as fibrocystic disease of the pancreas, cerebral palsy or childhood schizophrenia. There may therefore be further patients as yet unrecognized in long stay hospitals or mental deficiency institutions, or attending psychiatric clinics. These unfortunate children and their families can be helped (Riley, 1957) so that early recognition is important.

With the exception of one from Vienna (Tyndel, 1955), all the cases so far recorded have been from America or Canada (Forster and Tyndel, 1956). The following example is unusual in that the diagnosis was certain at the age of 8 months despite the absence of a family history of this condition.

\section{Case Report}

B.A. is the third child of Jewish parents. When she was born her father was aged 41 and her mother 39. Both had been healthy and there was no history of consanguinity. Their first child, a boy of 16 , and their second, a girl of $10 \frac{1}{2}$, were healthy and had both been breast fed for about nine months. B.A. was born at term by uncomplicated breech delivery following moderately severe maternal pre-eclampsia in the last month of pregnancy. Her birth weight was $6 \mathrm{lb}$. $4 \frac{1}{2} \mathrm{oz}$. She showed mild asphyxia at birth, but the only other abnormality noted then was that the fourth toe of each foot tended to cross medially under the third. Breast feeding was not established as the baby never sucked properly.

Advice was sought when she was 8 months old because of the following symptoms:

(1) Coldness of the extremities since the first few days of life and always present irrespective of clothing, room temperature or weather. Her hands and feet were frequently blue with cold, and sometimes swollen.
(2) Profuse sweating from her head and body since coming home from the maternity hospital. She invariably needed a complete change of dress and bed clothes each morning.

(3) Feeding difficulty had been present since birth and appeared to be due to dysphagia. Since the age of 1 month she began to put her thumb into her mouth after each mouthful of feed, apparently to assist swallowing. As a result, each feed took an hour or more and many were never finished. She frequently spat out or refused feeds, and never seemed hungry. Solids were consistently refused.

(4) Breath-holding attacks. These began at the age of 5 months and had increased in frequency from one or two to three or four daily. Either without warning or whilst crying, she would hold her breath, become cyanotic and lose consciousness for a few seconds. No sequelae had been noted.

(5) Emotional instability. She was easily and unpredictably upset, and to a much more profound degree than were her siblings at the same age. Sometimes she could not be consoled.

In spite of her discomfort and frustration, however, she had never produced any tears. There had been no vomiting, no excessive dribbling and her bowel actions were normal. There was no history of intercurrent illness, and she had never apparently been febrile. Her weight gain, though slow, had been fairly constant. She did not smile until 4 months old. Shortly after this she began to try to hold her head up, but at 7 months she was not sitting and made little attempt to play with toys.

Examination. B.A. was miserable but lusty. In spite of loud cries of misery and fear, there were no tears, though her conjunctivae were moist. Her hands were constantly active, but the movements were those of a child of 4 or 5 months of age. Throughout the examination she frequently interrupted her wailing by pushing her left thumb in her mouth to suck it only a few times before resuming her cries. There was mild plagiocephaly and slight asymmetry of the ears. The pulse was regular at 164 per minute. The heart was clinically normal, a quiet, short, blowing, apical mid-systolic murmur being considered physiological. Blood pressure: (whilst awake, by flush method) systolic $120 \mathrm{~mm}$. mercury in arm, $90 \mathrm{~mm}$. in leg; (whilst asleep, by auscultation) 106/60 mm. in arm, 80/50 mm. in leg. Though the hands and feet were abnormally cold and blue, the radial and tibial pulses were easily palpable. The trunk and limbs showed 
cutis marmorata but her scalp and neck were wet with perspiration. No abnormality was found in the chest, abdomen, genitalia, ears, or nose and no enlarged glands were felt. The limbs showed full ranges of movement.

An examination of the nervous system showed that the fundi and pupillary reactions were normal. There was absence of corneal reflexes, associated with hypo- or anaesthesia of the corneae;' some sensation was present in the rest of the area supplied by the trigeminal nerve, but the child did not resent a swab soaked in ammonia being held under her nose, nor did this produce any tears. The movement of the eyes and face was normal. There was a brisk gag reflex. Abnormal swallowing mechanism was noticed: a bolus of food when placed on the back of the tongue would be swallowed with an effort in two to three seconds; elsewhere in the mouth it was rejected. The limb movements were immature and there were no tendon reflexes present in arms or legs.

Developmental Assessment. (Gesell.) Made at 35 weeks by Dr. E. P. G. Michell. "The developmental profile was uneven and showed retardation in all areas. Gross motor performance was particularly affected; fine motor adaptive, less so. Predominantly, test behaviour was at the 20-24 week level."

Investigations. There were no cells, casts, albumen or organisms in the urine. A pooled specimen over several days showed no abnormal amount of pressor amines. Haemoglobin was $80 \%$; white cells, 18,700 per c.mm., polymorphs, $39 \%$; lymphocytes, $56 \%$; monocytes $4 \%$; eosinophils, $1 \%$. Blood urea, $29 \mathrm{mg}$. per $100 \mathrm{ml}$.; blood cholesterol $105 \mathrm{mg}$. per $100 \mathrm{ml}$.; serum calcium, $9.6 \mathrm{mg}$. per $100 \mathrm{ml}$.; serum alkaline phosphatase $24.8 \mathrm{~K}$-A units per $100 \mathrm{ml}$; serum sodium, potassium, chloride and bicarbonate levels normal; plasma electrophoretic pattern within normal limits. The Wassermann reaction was negative; a Mantoux test 1 in 1,000 was negative. Electrocardiogram rate 165 per minute; sinus rhythm; P.R. 0.11 second; Q.R.S. 0.04 second; electrical axis vertical; there was less evidence of right ventricular preponderance than is usual at this age; ST segments and
$\mathrm{T}$ waves were within normal limits. Radiographs of the chest and abdomen were normal. Bone development was compatible with age. A barium swallow was normal. Cerebrospinal fluid was clear and colourless; sugar, chlorides and protein were all within normal limits; there was no excess of globulin. Lange showed no reaction. An electroencephalogram showed no evidence of any paroxysmal disturbance or unilateral cerebral lesion. Subcutaneous injection of $0.125 \mathrm{mg}$. neostigmine bromide produced a few tears (Kroop, 1956).

Progress. During her 10-day stay in the ward she was kept in a cubicle of average temperature $70^{\circ} \mathrm{F}$. The extremities became pink and warm. The rectal temperature varied irregularly between $97 \cdot 0$ and $100 \cdot 2^{\circ} \mathrm{F}$. When she was asleep the pulse was usually 120 per minute but when she was awake it was contantly raised to 160 per minute. She had three short breath-holding attacks, all related to examination or handling by nursing staff. Feeds continued to take an hour or more and many were left unfinished. Her weight remained about $14 \frac{3}{4}$ lb.

She was discharged receiving phenobarbitone gr. $\frac{1}{4}$ twice daily. Subsequently there were only about six breath-holding attacks during the following 10 weeks. The blood pressure has once been as high as 146/86 mm. of mercury. One attack of bronchitis lasting three weeks occurred at the age of 9 months. At the age of 1 year she was less miserable than before admission. Developmental assessment (Gesell) at 53 weeks by Dr. E. P. G. Michell showed a similar pattern to that at 35 weeks. Her performance was on the whole at the 28-32 week level, but one test was performed at the 40-week level. At this time she began to show indifference to painful stimuli.

\section{Discussion}

This child shows many of the features of the syndrome as described in the literature. Other common but not essential features are not present and some cannot be assessed. Table 1 summarizes these.

TABLE 1

\begin{tabular}{|c|c|c|c|}
\hline Feature & Present & Not Present & Not Fully Assessed \\
\hline Hereditary factors & Jewish parents & $\begin{array}{l}\text { Occurrence in siblings } \\
\text { Consanguinity of parents }\end{array}$ & \\
\hline Autonomic dysfunction & $\begin{array}{l}\text { Absence of tears } \\
\text { Excessive sweating } \\
\text { Paroxysmal hypertension } \\
\text { Poor control of peripheral circulation } \\
\text { Abnormal swallowing mechanism }\end{array}$ & $\begin{array}{l}\text { Skin blotches } \\
\text { Bowel upsets } \\
\text { Excessive dribbling } \\
\text { Attacks of high fever }\end{array}$ & Postural hypotension \\
\hline Voluntary motor-disturbance & $\begin{array}{l}\text { Poor co-ordination } \\
\text { Absent tendon reflexes }\end{array}$ & Orthopaedic deformity & Dysarthria \\
\hline Sensory disturbance & Corneal anaesthesia & & $\begin{array}{l}\text { Indifference to pain } \\
\text { Dysaesthesia } \\
\text { Proprioceptive disturb- } \\
\text { ance }\end{array}$ \\
\hline Psychological features & $\begin{array}{l}\text { Breath-holding attacks } \\
\text { Emotional lability } \\
\text { Retarded development }\end{array}$ & Vomiting attacks & \\
\hline Other features & Retarded growth & $\begin{array}{l}\text { Frequent respiratory infections } \\
\text { Corneal ulceration }\end{array}$ & $\begin{array}{c}\text { Tendency to accidental } \\
\text { injury }\end{array}$ \\
\hline
\end{tabular}


She also had the typical facial expression, difficult to describe adequately, but apparently compounded of suspicion, fear and misery.

Of this diverse collection of symptoms, some are present so frequently as to be considered essential to the diagnosis. These are: (1) Jewish ancestry. (2) Reduced tear secretion. (3) Excessive sweating. (4) Feeding difficulty. (5) Cold hands and feet. (6) Postural hypotension. (7) Poor motor coordination. (8) Corneal anaesthesia. (9) Relative indifference to pain, and (10) Emotional lability.

A variable number of the other features in the table may be present. Also occasionally reported have been persistent leucocytosis, neonatal flaccidity and persistent thumb sucking. The predominating features tend to vary with age. Thus feeding difficulty is commonly the earliest symptom; absence of tears is not noteworthy before 2 months of age; motor inco-ordination is seldom appreciated before 6 months. After the age of 6 months breath-holding attacks begin, and parents may focus attention on apparent mental retardation or on excessive dribbling. Vomiting attacks usually predominate in those aged 2 to 5 years. Sensory disturbance and postural hypotension can be evaluated only after infancy.

The diagnosis in extreme infancy is not easily made, and usually doubt remains throughout the first year of life. Riley (1957) suggests that in the neonatal period at least the following should be present: (1) Family history. (2) Pronounced feeding difficulty and (3) Lack of deep tendon reflexes.

Family history, however, can never be more than suggestive, and has been found in only about a third of all cases so far reported. Feeding difficulty is common in newborn infants but in this condition it is marked and frequently shows no sign of ameliorating for several months. Though swallowing is more commonly reported to be abnormal, difficulty in sucking has also been noted. Tendon reflexes are not always absent in older cases. In some they vary from time to time, and it may be that they disappear as the child grows.

Moloshok and Reuben (1954) were able to gather the neonatal histories of 14 of their patients. They found that apart from feeding difficulty there was a high incidence of apnoeic or cyanotic attacks simulating atelectasis, hypothermia, attacks of high fever, excessive oral secretion, vomiting and failure to thrive. The present case suggests that profuse sweating and poor circulatory control may also occur in the neonatal period.

Differential Diagnosis. Provided that it is considered, familial dysautonomia is unlikely to be confused with other conditions. There are, how- ever, points of similarity with several commoner diseases in infancy. Thus the vasomotor instability, sweating, hyporeflexia and misery occur also in pink disease. This condition, however, rarely affects children under the age of 6 months, whereas dysautonomic children are abnormal from birth. Photophobia, severe skin irritation and increased urinary excretion of pressor amines (Farquhar, Crawford and Law, 1956) often found in pink disease, have not been described in dysautonomia. In the latter, feeding difficulty as opposed to anorexia is typical.

Because of frequent lower respiratory infections, poor nutritional state, sweating, hypotonia and febrile episodes, fibrocystic disease of the pancreas may be suspected. Suspicion may be heightened by radiographic demonstration of areas of consolidation, atelectasis or emphysema. These are usually attributed to aspiration of food or vomitus as a result of inco-ordinated swallowing. Moloshok and Moseley (1956) have suggested that increased bronchial secretion may be responsible, much as the changes in fibrocystic disease are related to the unduly viscid secretion throughout the respiratory tree. Though the duodenal juice may be viscid and scanty in dysautonomia, pancreatic function is normal (Shwachman, Leubner and Catzel, 1955).

Cerebral palsy may show similar motor defects but sensory and vascular disturbances are not marked. Rarely, absence of tears may be due to congenital absence of the lachrymal glands, sometimes associated with other congenital defects in the face, skull or cranial nerve nuclei (Sjögren and Eriksen, 1950).

Later in childhood several other conditions require differentiation. The attacks of fever, vomiting, abdominal pain, headache and sweating may simulate the periodic syndrome. In this condition and in migraine, however, there are usually no physical signs.

Less easy to disprove is the presence of a phaeochromocytoma. Smid and DuShane (1955) could find fewer than a dozen under the age of 10 recorded in the literature. Both a phaeochromocytoma and dysautonomia may produce paroxysms of headache, pallor, sweating, abdominal pain, peripheral vasoconstriction and hypertension. Phaeochromocytoma, however, is not accompanied by nervous abnormalities and the attacks respond well, if temporarily, to adrenolytic agents such as phentolamine or piperoxane; there is also a great increase in urinary excretion of pressor amines.

Many of the psychological features of dysautonomia may superficially resemble those of schizophrenia. Exaggerated response to emotional stress, 
withdrawal from surroundings in vomiting attacks, often with repetitive or self-injurious behaviour and apparent inability to concentrate, may all be seen in both conditions. Schizophrenic children may also show poor vasomotor control, muscle inco-ordination, and apparently retarded development. Examination, however, shows that dysautonomic children are not psychotic, nor is there any history suggesting precocious development followed by regression.

Finally some children with congenital indifference to pain have been described with absent tendon reflexes and retarded development, but there the similarity to dysautonomia ends.

Prognosis. The outlook as regards survival is uncertain. About a fifth of all the recorded cases have died, some in the first year of life, others in childhood. Most of the deaths seem to have been due to respiratory infection, with or without hyperpyrexia. At least one has been attributed to renal damage, and one child died following a haematemesis.

Of the survivors, the pattern of early development is becoming fairly well defined. Affected children remain below average height and weight. Their lives are punctuated by frequent illness and injury. The latter may begin with teething: by a combination of habitual rubbing of the tongue or cheek on teeth and indifference to pain, severe ulceration may result. Besides respiratory infection, corneal ulceration due to defective lachrymation is common. Motor performance is severely handicapped by inco-ordination and development is therefore retarded. Adaptation to these disabilities is poor.

No less a handicap is the psychological abnormality. The cycle of personality traits and their reactions in the family are described by Freedman, Helme, Havel, Eustis, Riley and Langford (1957). In infancy the situation is relatively simple. The affected infant is likely to be miserable and to show exaggeration of infantile reaction to stress. The case described here suggests that this is not entirely resistant to sedative therapy, but little information on the subject is available.

Later in childhood a more complicated situation develops. These children, realizing that they have unique and incurable physical handicaps, make many demands on their parents and become tyrannical. Yet they lack initiative and remain over-dependent on others. They tend to become very attached to adults other than their parents, especially women, and are rarely friendly to other children. The parents, even when the diagnosis is known to them, tend to feel afraid of their child's symptoms and to resent them. Some parents even feel guilty. Most try to gratify the child's inordinate demands. Such appeasement, especially when variable, reduces the child's sense of security. To the difficulty of controlling the "milieu interieur" is added that of trying to compensate for a changing social environment, and the whole cycle is enhanced. Partial or complete rejection by one or both parents may result.

The long term outlook is not known. The oldest patient so far recorded was 23 years old in 1957 (Riley, 1957). She had not fully compensated for her disabilities. Other patients are thought to be developing renal damage due to hypertension. Adult cases have never been described. It is not inherently impossible that adaptation, both physical and psychological, can eventually take place.

\section{Summary}

The clinical findings in a Jewish girl, aged 8 months, with familial dysautonomia are reported. The diagnosis was suggested by absence of tears, excessive sweating, paroxysmal hypertension, poor peripheral circulatory control and dysphagia. Poor muscle co-ordination, absence of tendon reflexes and corneal anaesthesia indicated that there was also disturbance of motor and sensory systems. Breath-holding attacks, emotional lability, retardation of development and relative failure to thrive were also present. Diagnosis is on clinical grounds alone.

The differential diagnosis in infancy includes pink disease, fibrocystic disease of the pancreas, cerebral palsy and congenital absence of lachrymal glands and in older children the periodic syndrome, schizophrenia and phaeochromocytoma.

Dysautonomia is not necessarily fatal, but the physical difficulties and psychological disturbances in child and family make the rearing of the child difficult.

I am grateful to Dr. H. V. L. Finlay for his permission to publish this account and also for much helpful advice and criticism. My thanks are also due to Dr. E. P. G. Michell for the developmental assessment.

\section{REFERENCES}

Farquhar, J. W., Crawford, T. B. B. and Law, W. (1956). Brit. med. J., 2, 276

Forster, W. and Tyndel, M. (1956). J. ment. Sci., 102, 345.

Freedman, A. M., Helme, W., Havel, J., Eustis, M. J., Riley, C. M. and Langford, W. S. (1957). Amer. J. Orthopsychiat., 27, 96. Kroop, I. G. (1956). J. Pediat., 48, 328

Moloshok, R. E. and Moseley, J. E. (1956). Pediatrics, 17, 327

and Reuben, R. N. (1954). J. Mt Sinai Hosp., 21, 137.

Riley, C. M. (1952). J. Amer. med. Ass., 149, 1532.

- (1957). Advanc. Pediat., 9, 157.

Day, R. L., Greeley, D. M. and Langford, W. S. (1949). Pediatrics, 3, 468.

Shwachman, H., Leubner, H. and Catzel, P. (1955). Advanc. Pediat. $7,257$.

Sjögren, H. and Eriksen, A. (1950). Brit. J. Ophthal., 34, 691.

Smid, A. C. and DuShane, J. W. (1955). Amer. J. Dis. Child., 90, 81

Tyndel, M. (1955). Wien. med. Wschr., 105, 189. 